A: Gestão Ambiental e Políticas Públicas

\title{
PONTAL DA BARRA - UMA QUESTÃO DE VULNERABILIDADE SOCIAL
}

Gabriela Tombini Ponzi - gtombini.ponzi@gmail.com Universidade Federal de Pelotas - UFPel

Bruna Wagner Irion - bruirion@ gmail.com

Universidade Federal de Pelotas - UFPel

Diuliana Leandro - diuliana.leandro@ gmail.com

Universidade Federal de Pelotas - UFPel 


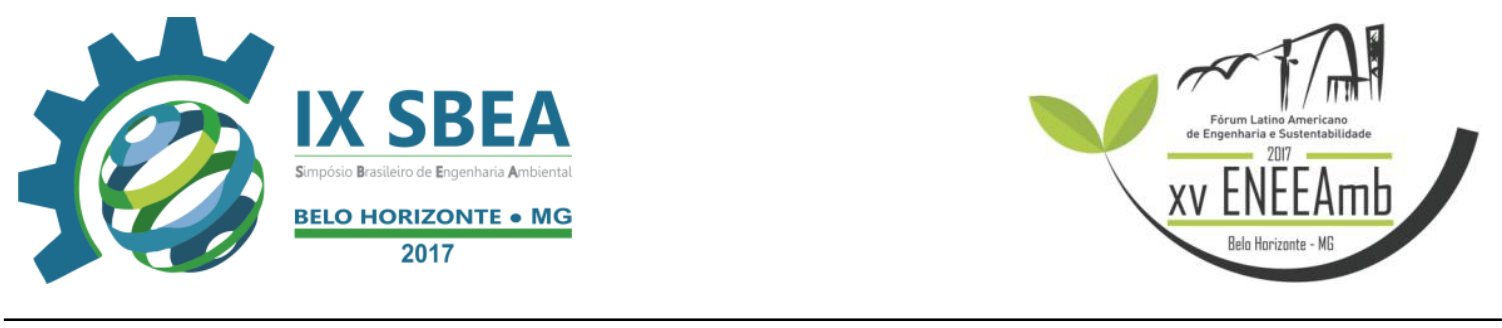

\section{RESUMO}

Através do uso do sistema de informações geográgificas QGIS, uma plataforma livre, foi possível analisar a situação da vila de pescadores do Pontal da Barra, município de Pelotas, localizada dentro de uma área de preservação permanente (APP) por uma perspectiva de vulnerabilidade social. Ao longo do documento foram apresentados os parâmetros utilizados na geração do índice de vulneravilidade social (IVS) e correlacionando o IVS do município de Pelotas com outros dos municípios próximos assim como o da capital, Porto Alegre e o IVS do estado do Rio Grande do Sul. A partir destes dados foi feita uma análise da infra-estrutura da área do Pontal da Barra através de mapas temáticos e das inundações que acometem a região em época de grandes chuvas. Utilizando-se do Plano Diretor do município foi apontado a necessidade de regularizar as ocupações da vila de pescadores com a utilização de politicas públicas visando melhorar a qualidade de vida dos moradores da região.

Palavras-chaves: Vulnerabilidade social, APP, SIG, políticas públicas, Pontal da Barra

\section{INTRODUÇÃO}

A vulnerabilidade diz respeito ao potencial de perda. Assim como a perda varia geograficamente, através do tempo e das diferentes classes sociais a vulnerabilidade também transita entre esses aspectos (Cutter, 2003). A vulnerabilidade social está intrinsecamente relacionada ao espaço que o sujeito ocupa na sociedade e sua terminologia, embora amplamente aplicada, engloba um complexo campo conceitual constituído por diferente concepções e dimensões que podem voltar-se para o enfoque econômico, ambiental, de saúde, de direitos, entre tantos outros (Monteiro, 2012). A vulnerabilidade social abrange a parcela da população que está à margem da sociedade, os setores mais desprovidos (utilizando de indicadores de acesso ou de carências das necessidades básicas) (Monteiro, 2012).

A partir deste contexto percebe-se que a vulnerabilidade social passa a ser entendida a partir de múltiplos condicionantes. A qual, segundo Paulilo (1999), não é uma essência ou algo inerente a algumas pessoas e a alguns grupos, mas diz respeito a determinadas condições e circunstâncias que podem ser minimizadas ou revertidas" 


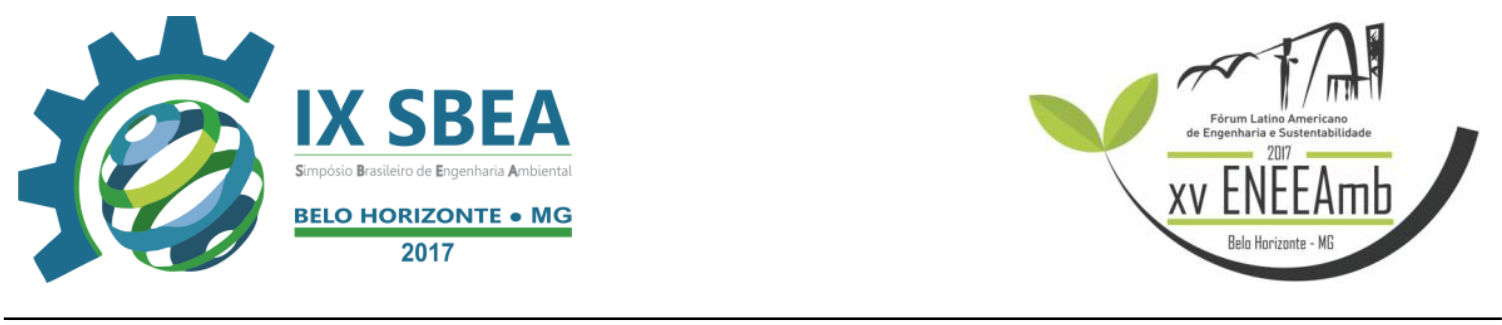

Os principais indicadores utilizados para definir um indivíduo em situação de vulnerabilidade social são as condições precárias de moradia e saneamento, meios de subsistência inexistentes, ausência de um ambiente familiar. Encontrando-se em um estágio de risco social -quando o indivíduo deixa de ter condições de usufruir dos mesmos direitos e deveres que outros cidadãos. Como consequência da situação que se encontram acabam perdendo sua representatividade na sociedade, passando a ser invisíveis a grande parcela da população e aos órgãos públicos. Necessitando de amparo das políticas públicas, que se constituem de fundamental importância caracterizando-se como um instrumento da garantia de direitos condições dignas de vida (Monteiro, 2012).

O Rio Grande do Sul de acordo com o Ministério das Cidades, por meio da Secretaria Nacional de Saneamento Ambiental (SNSA), no do Sistema Nacional de Informações sobre Saneamento (SNIS) nos relatórios de 2015 apresenta que 87,18\% dos domicílios possuem água tratada e desses somente $29,4 \%$ apresentam tratamento de esgoto. Esse dado alarmante demonstra que as políticas públicas voltadas para o saneamento básico são de extrema importância e urgência e, também, que a população que se encontra em situação de vulnerabilidade social não se limita aos grandes centros urbanos, mas é um problema generalizado no estado.

A partir da conceitualização de vulnerabilidade social é possível analisar a situação do município de Pelotas/Rio Grande do Sul, no qual o índice passou de 0,316 em 2000 para 0,224 em 2010. Os parâmetros utilizados para geração desses índices foram: renda e trabalho, infraestrutura urbana e capital humano. Essa melhora no índice, pode significar um aumento nas políticas públicas voltadas para indivíduos em situação de risco.

Quando se compara os índices de vulnerabilidade social (IVS) Pelotas com os municípios vizinhos: Rio Grande, Capão do Leão, Canguçu, São Lourenço do Sul, Pedro Osório e a capital, Porto Alegre, pode-se perceber as diferenças regionais, principalmente sabendo que Pelotas na Zona Sul é dentre estes o município com maior população e orçamento do estado. Analisando o panorama do IVS para esses municípios e comparando-o com Porto Alegre e com o estado do Rio Grande do sul como um todo podemos concluir que houve uma melhora significativa no índices de IVS, como é 


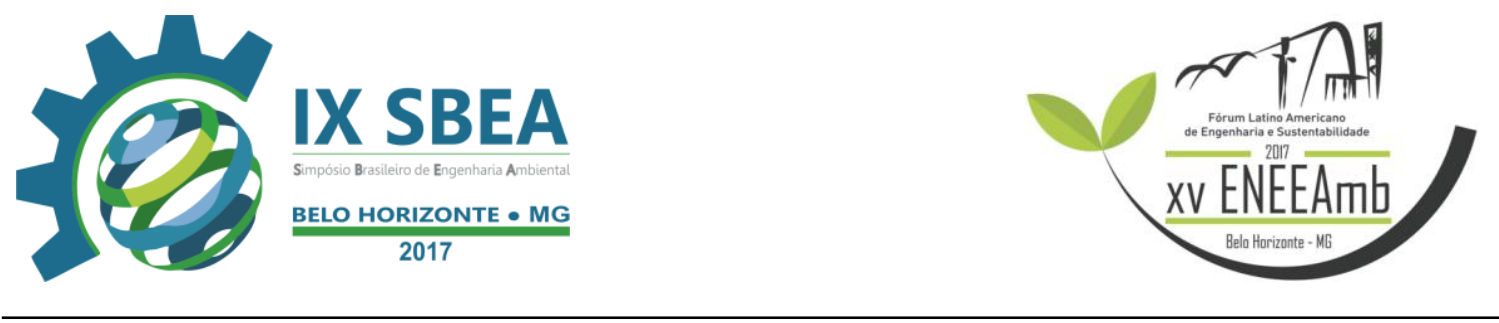

possível observar na Tabela 1. O IVS do município de Pelotas é o menor dentre os analisados, inclusive é melhor que a média do estado, tanto nos anos de 2000 como de 2010. Alguns dos possíveis motivos que o IVS de Pelotas apresente os menores valores, ou seja, o melhor índice entre os analisados possivelmente podem estar relacionado ao fato de ser a terceira maior cidade do estado, de possuir um orçamento de mais de 327 milhões de reais para o ano de 2017 ao mesmo tempo que tem uma população de 343.651 habitantes (IBGE, 2010), tornando as políticas públicas assistenciais mais efetivas.

Tabela 1- Índice de Vulnerabilidade Social dos municípios e do estado do Rio Grande do Sul

\begin{tabular}{|ccc|}
\hline \multicolumn{3}{|c|}{ Índice de Vulnerabilidade Social } \\
\hline Munícipio & $\mathbf{2 0 0 0}$ & $\mathbf{2 0 1 0}$ \\
\hline Pelotas & 0.316 & 0.224 \\
Canguçu & 0.391 & 0.249 \\
Pedro Osório & 0.394 & 0.312 \\
Capão do Leão & 0.390 & 0.290 \\
Rio Grande & 0.362 & 0.270 \\
São Lourenço & 0.368 & 0.269 \\
Porto Alegre & 0.324 & 0.249 \\
Camaquã & 0.336 & 0.233 \\
\hline Rio Grande do Sul & 0.327 & 0.234 \\
\hline
\end{tabular}

Se levássemos em conta apenas a melhora do índice poder-se-ia afirmar que houve uma preocupação pelo setor público para com esses indivíduos, porém sabe-se que essa melhora dos indicadores de vulnerabilidade social não ocorreu de forma homogênea na cidade como um todo e, sim, provavelmente na região central e em muitos bairros não houve quaisquer melhoras.

Essa análise poderia ser mais fiel a realidade se as análises expressassem o índice de vulnerabilidade social de cada um dos bairros do município, auxiliando, inclusive, na tomada de decisões para tornar as ações mais efetivas.

A situação de vulnerabilidade social nos grandes centros urbanos do país está, muitas vezes relacionada ao êxodo rural. Uma vez que essa expansão e saturação das 


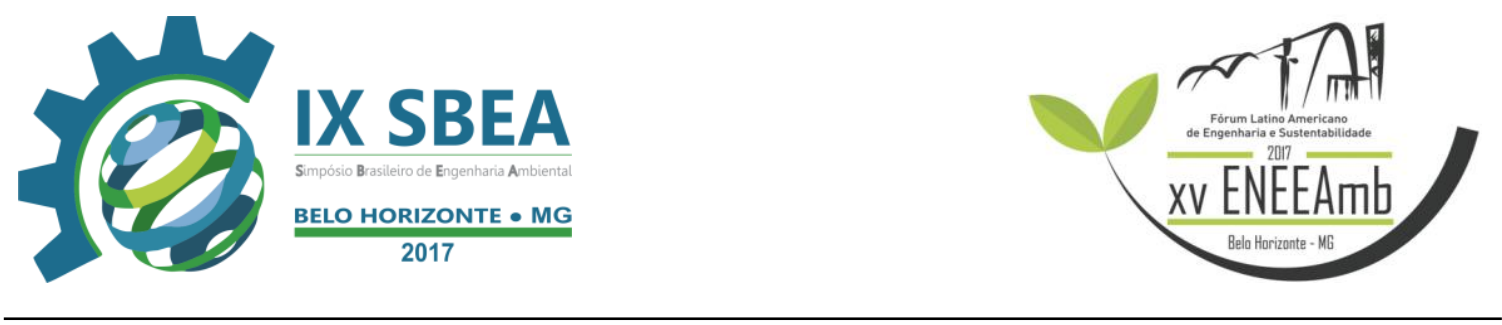

cidades em sua maioria não se deu de forma planejada e organizada no Brasil. Desta forma, com o crescimento da população urbana aumentou a demanda por moradias, esse aliado a pobreza tem gerado um avanço nas fronteiras habitacionais que muitas vezes acabam avançando sobre zonas ambientais de preservação permanente (Irion et al., 2016).

Dentro deste contexto surgem duas questões relevantes, ao mesmo tempo em que se necessita uma intervenção do estado para a garantia de preservação do meio ambiente também é importante refletir sobre o futuro das populações consolidadas que já ocupam áreas ambientalmente frágeis. Muitas dessas áreas ocupadas são Áreas de Preservação Permanente (APP), as quais são áreas protegidas por lei, sendo estas cobertas ou não por vegetação nativa, mas que possuem uma diversidade ambiental complexa em diversos aspectos, como fauna, flora, biodiversidade e recursos hídricos.

Assim o objetivo deste trabalhoé relacionar as áreas de preservação permanente do Pontal da Barra/RS com a situação de vulnerabilidade social dos indivíduos que ali residem. Para tal realizou-se a análise da expansão antrópica através da análise temporal de imagens de satélite dos anos de 2004 e 2015, e com o auxílio do plano diretor do município.

\section{METODOLOGIA}

A área de estudo está localizada na região do Pontal da Barra, balneário do Laranjal, no município de Pelotas no estado do Rio Grande do Sul, mais especificamente na vila de pescadores que se situa bem na ponta da região, que pode ser identificada por apresentar uma "ponta" de terra, sendo demarcada por limites hídricos pelo canal São Gonçalo e a Laguna dos Patos. Essa área de acordo com a legislação federal é classificada como RPPN (22/09/19949), e possui 65,33 hectares de área e atualmente é propriedade de Loteamentos e Minerações Gerais Ltda (Irion, 2016).

A área prioritária a ser conservada é a Várzea do Canal São Gonçalo (Áreas Prioritárias para Conservação, Uso Sustentável e Repartição dos Benefícios da Biodiversidade Brasileira) entre a laguna dos Patos (Pontal da Barra) e a foz do arroio Pelotas, chegando até as dunas do Laranjal. É dentro desta área que está a RPPN do Pontal 
da Barra, e advindas desta, que se originam as definiçõoes de outras unidades de conservação estando condicionadas ao não reconhecimento da zona de amortecimento por parte da legislação estadual (PROGRAMA 5, Definição da Várzea do Canal São Gonçalo como Área Prioritária para a Conservação).

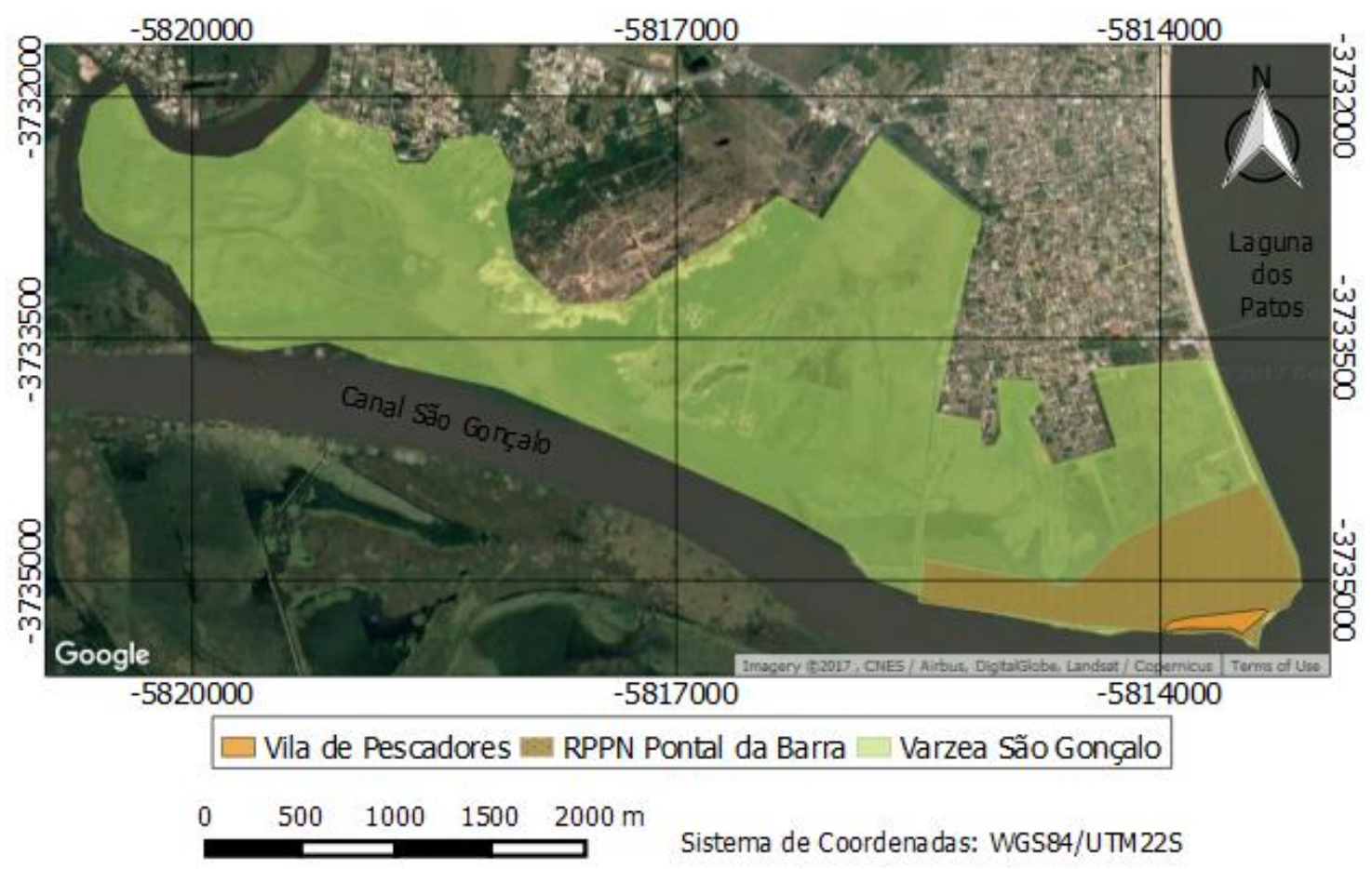

Figura 1: Área de RPPN do Pontal da Barra e da Várzea do Canal São Gonçalo.

Na figura 1 pode-se observar de um modo geral a área de estudo, a delimitação da Várzea do Canal São Gonçalo, da RPPN do Pontal da Barra e da vila de pescadores. Sendo o corpo hídrico abaixo do polígono verde o Canal São Gonçalo que desagua na Laguna dos Patos (a direita na imagem), que se inicia a partir do limite da RPPN. Enquanto na figura 2 tem-se em detalhe a área da vila de pescadores que é o foco deste trabalho localizada no interior da RPPN. 

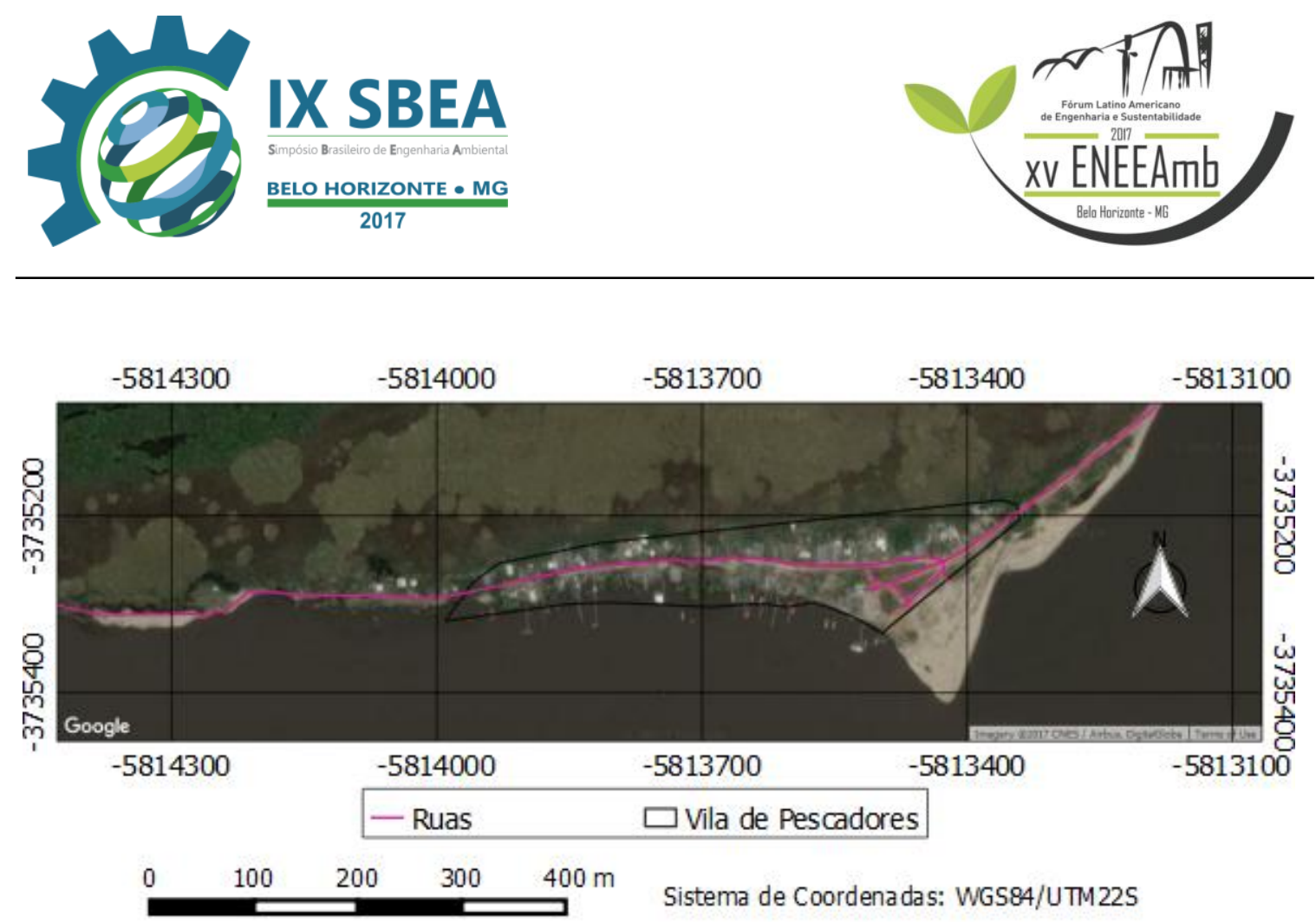

Figura 2: Vila de Pescadores situada no Pontal da Barra. Fonte: Open layers do Google Earth.

Para a realização do presente trabalho utilizou-se o sistema de informações geográficas QGIS versão 2.10.1, uma plataforma livre, a qual possibilitou a visualização, vetorização, manipulação, integração e análise de dados espaciais e também a geração de mapas temáticos. O programa QGIS permitiu através de dados matriciais (ortofotos e imagens de satélite) a visualização e delimitação da ação antrópica da região bem como os canais de drenagem, bacias de detenção e pontos de inundação da área de estudo. Para a análise da região utilizou-se a ortofoto em escala 1:2000 cedida pelo coordenador do órgão de Defesa Civil do municipal de Pelotas, Tenente Paulo Darci dos Santos que recobria parcialmente a área. E através da ferramenta OpenLayers Pluggin, a qual possibilita acesso as imagens de satélite do da empresa Digital Globe, a mesma base do Google Earth, pode-se complementar as informações da ortofotos da prefeitura.

A partir dos dados cedidos foi feita uma análise temporal da ocupação antrópica que compreende os anos de 2003 a 2016 com dados dos seguintes anos: 2003, 2013 e 2016. Houve um crescimento da urbanização em local de RPPN sendo esta mais significativa entre os anos de 2003 e 2013, no qual o número de edificações passou de 115 para 164 enquanto em 2016 a área contava com um total de 179 edificações. 


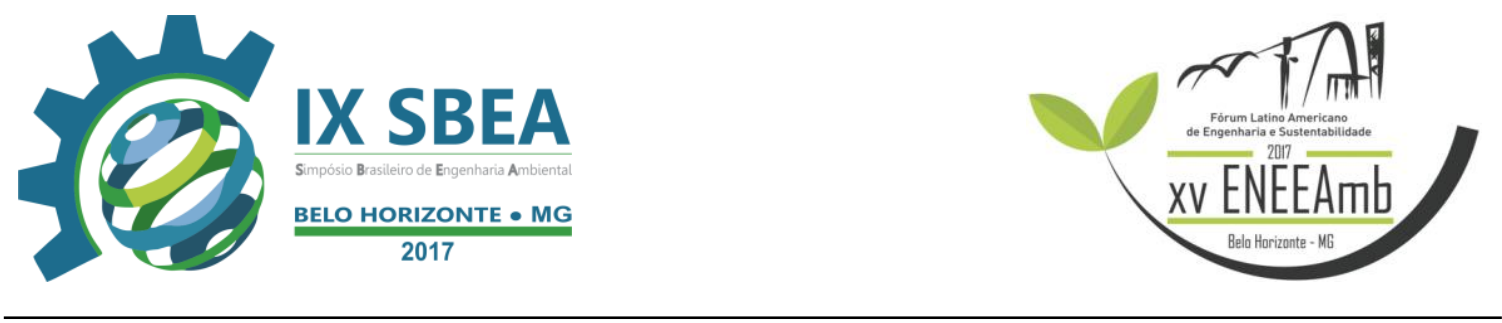

Tabela 2- Aumento da ocupação antrópica na Vila de Pescadores

\begin{tabular}{|lcc|}
\hline \multicolumn{3}{|c|}{ Ocupação Antrópica na Vila de Pescadores } \\
\hline Ano & Número de Edificações & Aumento de Edificações (\%) \\
2003 & 115 & - \\
2013 & 164 & 42,6 \\
2016 & 179 & 9,14 \\
\hline
\end{tabular}

O aumento significativo observado entre os anos de 2003 e de 2013 acontece, principalmente, pela falta de dados entre os respectivos anos, causando a impressão que o aumento do número de edificações na região dá-se de forma desenfreada. Porém quando a análise do crescimento é realizada com um intervalo de tempo menor, 3 anos, entre 2013 e 2016, percebe-se que essa expansão não acontece de forma tão rápida.

Considerou-se para as análises as informações advindas do plano diretor do município de Pelotas, o qual considera-se Áreas de Preservação Permanente (APP) áreas situadas a cem metros para cursos d'água maior que cinquenta metros, porém a área de APP diminui para trinta metros para os cursos d'água situados em áreas urbanas consolidadas. Esta última consideração se aplica para o Pontal da Barra. Na figura 4 é possível observar os limites de APP na região que foram delimitados no QGIS.

Ainda considerando o plano diretor de Pelotas a região passa a ser Área de Preservação Permanete Ocupada (APPO). Que significa que é uma área onde houve processos de ocupação e uso consolidados, que atendam o interesse social, público e comunitário, podendo ser regulamentados mediante ações mitigatórias e compensatórias e de recuperação do meio ambiente, proporcionais ao dano causado e sua escala. (PLANO DIRETOR, 2008 ). E segundo a resolução do CONAMA nº 369 de 2006 existem casos excepcionais, de utilidade pública, interesse social ou baixo impacto ambiental que possibilitam a intervenção ou supressão de vegetação nativa em APP. 
Ou seja, a vila de pescadores do Pontal da Barra é passível de análise quanto a sua regularização de uso e ocupação pois tem uma função social e de interesse coletivo, necessitando ser submetida à análise e definições específicas para esta área.

\section{RESULTADOS E DISCUSSÃO}

Essa pesquisa possui como foco central o risco social da comunidade de pescadores do Pontal da Barra, para tal se analisou como se dá a ocupação antrópica da área, assim como a questão da infraestrutura da região, além da interação com a drenagem do local, já que historicamente a comunidade é afetada por eventos de inundação.

Na figura 3 é possível observar os canais de drenagem e as bacias de denteção da área, porém em épocas de altos índices pluviométricos essa infra-estrutura se mostra ineficiente acarretando na inundação da região. Em outubro de 2015, o acumulado de chuva foi de 321,4 (dados registrados numa Estação Metereológica Automática da EMBRAPA), sendo o Pontal da barra uma das regiões mais afetadas, fazendo com que fosse decretado estado de emergência no município.

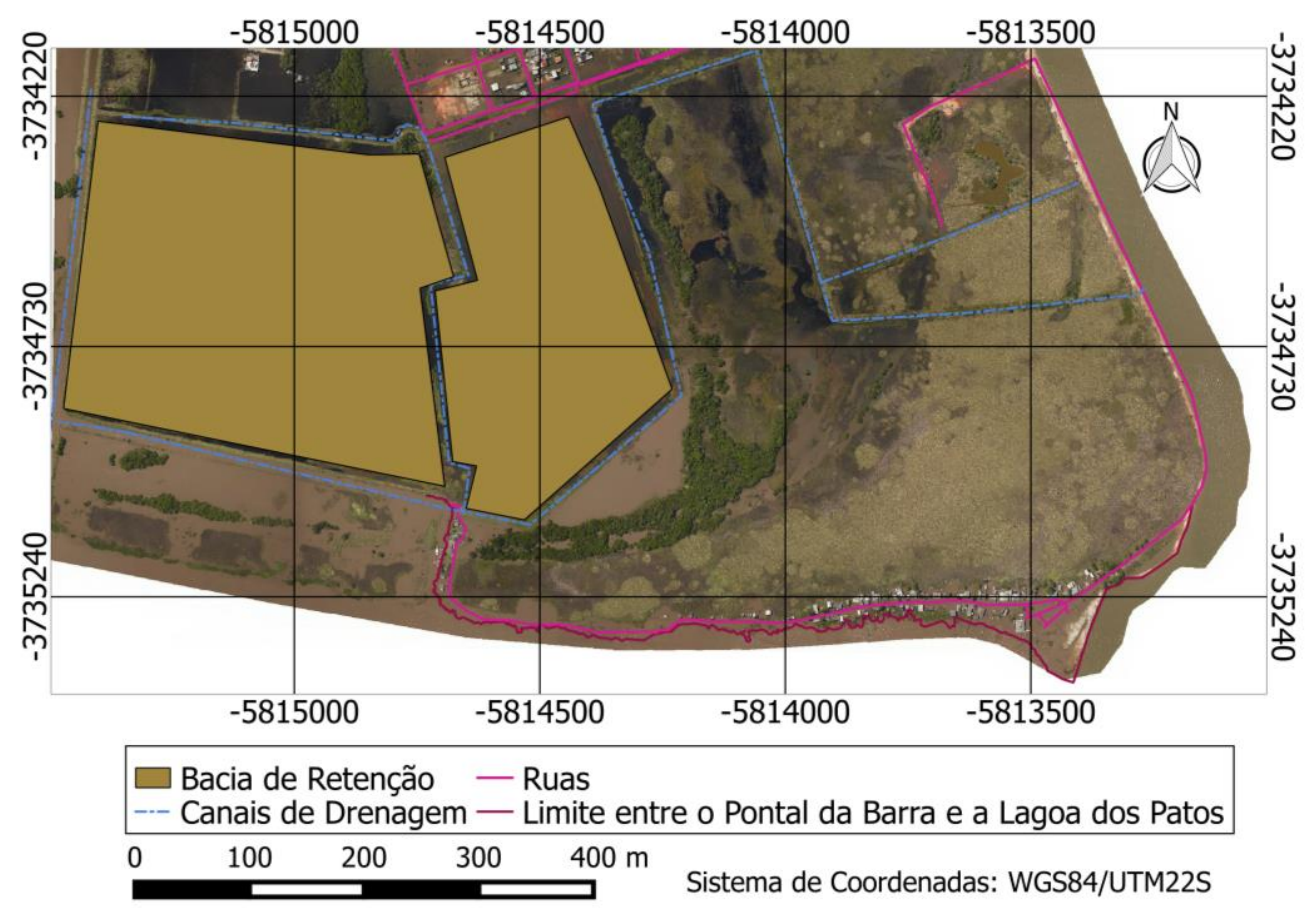

Figura 3: Canais de drenagem e bacia de retenção do Pontal da Barra. 


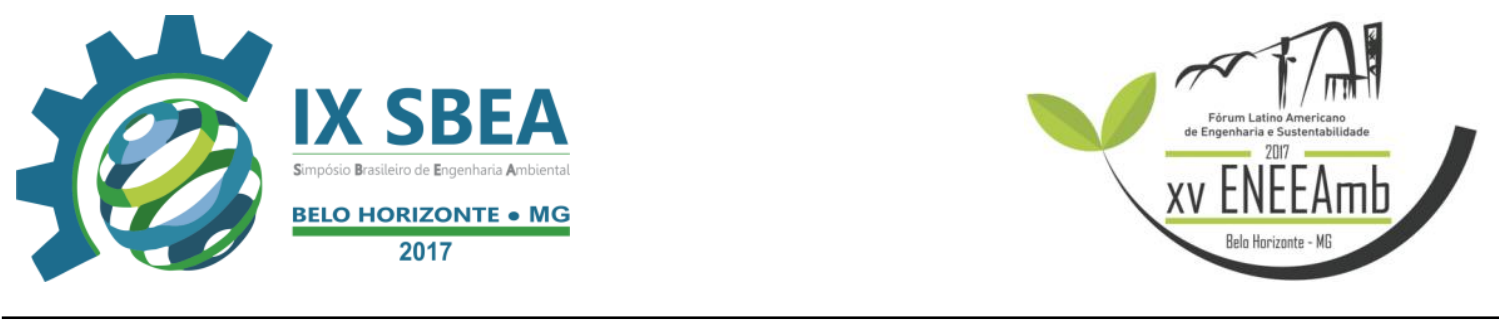

Através da análise da figura 4 é possível observar a da comunidade de pescadores durante a época de chuvas, colocando de uma forma mais concreta a situação de vulnerabilidade social que os moradores da região se encontram. Ao mesmo tempo em que se pode observar que a comunidade de pescadores se encontra dentro dos limites da APP quase que inteiramente.

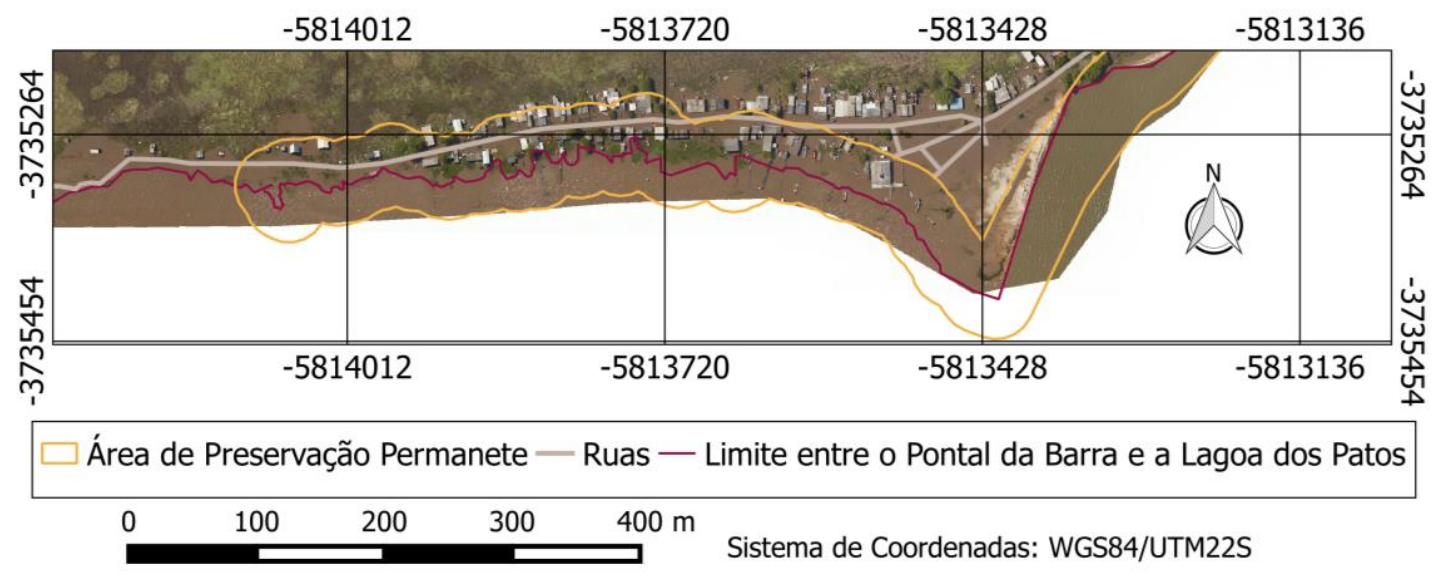

Figura 4: Comunidade de Pescadores inundada.

A situação se torna mais delicada quando se percebe que a região não é contemplada com rede de coleta de esgoto (dados fornecido pelo SANEP). Sendo de responsabilidade dos moradores da região a instalação foças sépticas e de poços negros para o tratamento do esgoto da região. A falta de saneamento básico está relacionada, também, com a disposição inadequada de resíduos, e acarreta na proliferação de doenças como a leptospirose, hepatite $\mathrm{A}$, e acaba represnetando mais um risco a comunidade.

\section{CONCLUSÕES/RECOMENDAÇÕES}

É inegável que a comunidade de pescadores do Pontal da Barra se encontra em situação de vulnerabilidade social e a partir desse entendimento é necessária a tomada de medidas para que haja uma melhora significativa na qualidade de vida desses indivíduos. A retirada dos moradores dessa área não seria a ação mais efetiva, uma vez que eles, provavelmente, acabariam retornando para o local, pois os moradores estabeleceram um vínculo entre si e com o ambiente. 


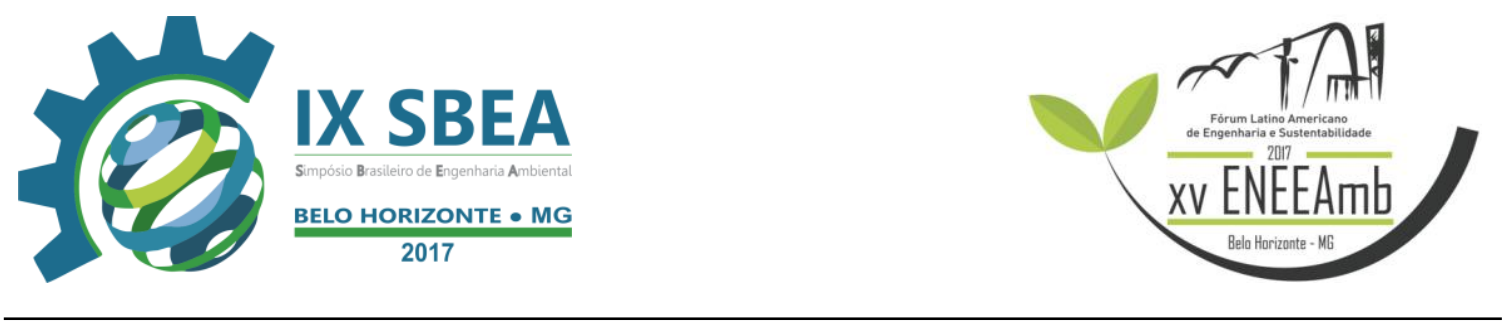

Tendo em vista a preservação ambiental da região seria mais interessante utilizarse de políticas públicas, abrangendo etapas educativas de coordenação e de realização, visando uma melhoria da infraestrutura da região. Combinando aspectos da percepção ambiental e das várias influências contextuais que tem um efeito do comportamento dos indivíduos sobre o ambiente. Uma vez que, segundo a psicologia ambiental, determinados estímulos ambientais podem encorajar ações adaptativas ou soluções de problemas.

\section{REFERÊNCIAS BIBLIOGRÁFICAS}

MONTEIRO, S.R.R.P. O marco conceitual da vulnerabilidade social. Sociedade em Debate, Pelotas, 17(2) p.19-40, 2011

TOZZI, M.; OTA, J. Vertedouro em degraus. Revista da Vinci, Curitiba, v.1, n.1, p. 928, 2004.

VERDUGO, C,V. Psicologia ambiental: objeto, "realidades" sócio-físicas e visões culturais de interações ambiente-comportamento. Psicologia, USP, p. 71-87, 2005.

PARFITT, M, C. Áreas especiais de interesse do ambiente natural: uma metodologia de planejamento e gestão. Porto Alegre, 224, p., 2010. Dissertação (Doutorado) Universidade Federal do Rio Grande do Sul

IRION, B.W,VIEIRA, D.D.S, LEANDRO, D., Avaliação Temporal dos processos de urbanização sob áreas de preservação permanete do Pontal da Barra- Pelotas/RS. In: XXV Ceminário de Iniciação http://cti.ufpel.edu.br/siepe/arquivos/2016/MD_04294.pdf

PREFEITURA DE PELOTAS. Plano diretor III. Disponível em: http://www.pelotas.com.br/politica_urbana_ambiental/planejamento_urbano/III_plano_ diretor/lei_iii_plano_diretor/arquivos/lei_5502.pdf acesso: 30/05/2017

PREFEITURA DE PELOTAS. Orçamento. Disponível em: http://www.pelotas.rs.gov.br/noticias/detalhe.php?controle $=\mathrm{MjAxNi0wOS0yMQ== \& co}$ dnoticia $=42950$ acessso: $28 / 05 / 2017$

ATLAS DA VULNERABILIDADE SOCIAL. Índice de vulnerabilidade social. Disponível em: http://ivs.ipea.gov.br/ivs/pt/consulta/ acesso: 25/05/2017

EMBRAPA, banco de dados. Disponível em: http://agromet.cpact.embrapa.br/online/Current_Monitor.htm acesso:30/05/2017

Editorial, Lenda urbana sobre internações devida à falta de saneamento. Disponível em: http://www.scielo.br/pdf/\%0D/csp/v21n4/01.pdf acesso:30/05/2017 